\title{
Determinism and plasticity of fish schooling behaviour as exemplified by the South Pacific jack mackerel Trachurus murphyi
}

\author{
Arnaud Bertrand ${ }^{1, *}$, Maria Angela Barbieri ${ }^{2,3}{ }^{,}$François Gerlotto $^{1}$, Francisco Leiva ${ }^{3}$, \\ José Córdova ${ }^{2}$
}

\author{
${ }^{1}$ Institut de Recherche pour le Développement, Centre de Recherche Halieutique Méditerranéenne et Tropicale, \\ Avenue Jean Monnet, BP 171, 34203 Sète Cedex, France \\ ${ }^{2}$ Instituto de Fomento Pesquero, Blanco 839, Casilla 8-V, Valparaíso, Chile \\ ${ }^{3}$ Escuela de Ciencias del Mar, Pontificia Universidad Católica de Valparaíso, Av. Altamirano 1480 , \\ Casilla 1020, Valparaíso, Chile
}

\begin{abstract}
Pelagic fish schools are thought to show a general pattern of dispersion at night and aggregation within schools during the day. This pattern is often accepted as the major rule driving most of the other physiological, biological and ecological processes. Foraging on mobile prey, for instance, is assumed to be enhanced by schooling behaviour. Current theory assumes then that foraging is only possible for obligatory gregarious predatory fish from dawn to dusk. However, offshore mesopelagic communities perform vertical migrations and are out of reach for most oceanic pelagic predators during the day (with the exception of some apex predators, e.g. swordfish or bigeye tuna). To investigate how fish may overcome this apparent contradiction, we studied the 3-dimensional spatial strategy of the South Pacific jack mackerel Trachurus murphyi according to the abiotic and biotic conditions of the habitat. Data came from acoustic surveys performed in central Chile in 1997, 1998 and 1999. Our results show that the jack mackerel distribution was driven by prey during the night when foraging, and related to the hydrology when resting during the day in the upper part of the oxycline. Fish were more aggregated at night than during the day, probably because jack mackerel cycles of schooling behaviour depend primarily on prey availability. This 'atypical' behaviour could be an adaptation of gregarious pelagic fish to an oceanic ecosystem. Fish schooling behaviour is not necessarily driven directly by the diel cycle; rather, it can be functional and depends on prey availability.
\end{abstract}

KEY WORDS: Fish schooling behaviour - Fish adaptive strategies · Diel migration · Predator-prey relationships · Pelagic ecosystem functioning · Dissolved oxygen · Jack mackerel

\section{INTRODUCTION}

Gregarious pelagic fish show a general pattern of dispersion at night and aggregation in schools during the day (Azzali et al. 1985, Fréon et al. 1996, Fréon \& Misund 1999, Cardinale et al. 2003). Foraging on mobile prey is assumed to be enhanced by schooling behaviour (Pitcher \& Parrish 1993). Therefore, trophic activities have to be in accordance with the diel cycle. However, offshore, main mesopelagic communities perform vertical migrations and become unavailable to most predators during the day (with the exception of some large species adapted to foraging individually or in small groups on the deep scattering layers, e.g. bigeye tuna Thunnus obesus, see Bertrand et al. 2002a). This is also the case for the highly migratory (Arntz \& Fahrbach 1996) oceanic jack mackerel Trachurus murphyi in the South 
Pacific. This obligatory gregarious fish is an opportunistic forager (Konchina 1981) with a very large distribution range, from the equator to the austral region of Chile and from South America to New Zealand and Tasmania (Serra 1991, Grechina 1998). It exploits a wide range of oceanographic conditions and thereby copes with climatic disturbance by moving to favourable areas (Bertrand et al. 2004b). Off Chile, the main horizontal migration pattern of jack mackerel consists of an offshore spawning migration in spring and an inshore feeding migration in autumn and winter (Serra 1991).

Gregarious fish have had to develop adaptive capabilities and strategies to manage foraging on vertically migrating mobile prey in a highly stratified vertical habitat. Indeed, Trachurus murphyi presents 'atypical' schooling behaviour (Bertrand et al. 2004a), being more aggregated during the night than during the day (at least during its feeding migration along the Chilean coast in austral winter). Bertrand et al. (2004a) hypothesised that this pattern was related to the fishes' nocturnally active foraging behaviour on the migrant mesopelagic community. The importance of prey availability in schooling behaviour for jack mackerel has already been touched on (Pitcher \& Parrish 1993), but the mechanisms have not been described. We investigated this question by studying the local 3D spatial strategy of the South Pacific jack mackerel as related to the abiotic and biotic conditions of the habitat, through an integrative approach. Indeed, fish spatial characteristics, addressed through a morphological coding of fish echo traces (Petitgas \& Levenez 1996, Barbieri et al. 1998, Reid 2000, Bertrand et al. 2004a), can be very informative with respect to the functional relationships of fish with the biotic and abiotic characteristics of the ecosystem. Among the abiotic parameters, we have focused particularly on dissolved oxygen (DO), a parameter known to play a major role in ecosystem structuring and community distribution and interaction in the vertical plane (e.g. Sameoto 1986, Kinzer et al. 1993, Bertrand et al. 1999, 2002b, Wishner et al. 2000). This parameter is particularly important in the Humboldt Current system, where an intense oxygen minimum zone (OMZ) is present (Ecribano et al. 2004). We thus aimed to check the hypothesis that the schooling behaviour of fish is driven mainly by a motivation to forage on prey which are cyclically available within the habitat of the fish, independently of the diel light-intensity signal. If such functional processes are essential in fish schooling behaviour, the 'atypical' behaviour observed in South Pacific jack mackerel would be typical of fish behaviour in specific habitat conditions.

\section{MATERIALS AND METHODS}

Data came from 3 cruises during which the acoustic assessment of jack mackerel Trachurus murphyi biomass was performed onboard the R/V 'Abate Molina' in austral autumn to winter: 5 May-17 June 1997, 3 June-20 July 1998 and 15 May-30 June 1999 (Córdova et al. 1998, 1999, 2000). The study area was the main jack mackerel fishing ground (Fig. 1) in central Chile $\left(32^{\circ} \mathrm{S}\right.$ to $\left.40^{\circ} \mathrm{S}\right)$. Survey design consisted of parallel transects running from 5 nautical miles (1 nautical mile $=1852 \mathrm{~m}$ ) to 200 nautical miles offshore for even transects and to 100 nautical miles for odd transects. Inter-transect distance was 20 to 100 nautical miles from the coast and 40 nautical miles outside this area.

Acoustic data. Acoustic data were collected with a SIMRAD EK500 echo sounder with a $38 \mathrm{kHz}$ splitbeam hull-mounted transducer (ES38B). The water column was sampled up to a depth of $500 \mathrm{~m}$, and the nautical area scattering coefficient, $s_{\mathrm{A}}$ (acoustic symbols and units used in the present paper are those proposed by MacLennan et al. 2002), was integrated in 0.5 nautical mile elementary sampling distance units (ESDU). In each ESDU, acoustic energy was available in 4 layers in $1997(3-25 \mathrm{~m}, 5-100 \mathrm{~m}, 100-200 \mathrm{~m}$, 200-500 m) and 7 layers (3-25 m, 25-50 m, 50-100 m, 100-200 m, 200-300 m, 300-400 m, 400-500 m) in

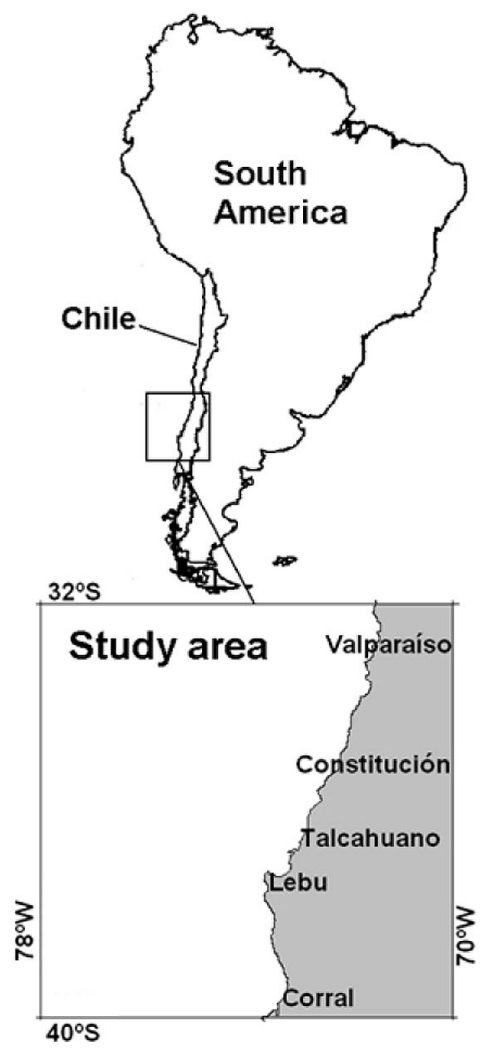

Fig. 1. Study area in the South Pacific 
1998 and 1999. For the main statistical analyses, $s_{\mathrm{A}}$ was normalised using a $\log (x+1)$ transformation.

Acoustic energy not assigned to fish resources was considered an indicator of the abundance of jack mackerel prey, mainly euphausiids and mesopelagic fish (Bertrand et al. 2004a). For each layer, in each ESDU, the acoustic energy was partitioned into 'resource' and 'index of prey biomass'. In central Chile, the main pelagic fish resources are jack mackerel, the common sardine Strangomera bentinki and the anchovy Engraulis ringens, but only jack mackerel is considered in this study. Species determination was obtained from scrutinising echo traces and in situ sampling by pelagic trawling (Córdova et al. 1998, 1999, 2000). A total of 43, 29 and 36 pelagic trawl samples were taken in 1997, 1998 and 1999, respectively, in which jack mackerel represented 92.1, 76.5 and $86.4 \%$ of total catches in weight.

Each ESDU was classified according to time. Day was defined as the period from 09:00 to 17:00 h; dusk, from 17:00 to $19: 00 \mathrm{~h}$; night, from 19:00 to $07: 00 \mathrm{~h}$; and dawn, from 07:00 to 09:00 h (local time). ESDUs were also classified according to the topography. In this study we used only data from the oceanic domain (seabed depth deeper than $800 \mathrm{~m}$ ), where most of the jack mackerel were distributed (Bertrand et al. 2004a) and almost no other fish resources were present $(<1 \%$ of total 'resource' $s_{\mathrm{A}}$ and $<4 \%$ of total trawl catches). We also focused mainly on day and night periods.

In addition to acoustic energy data by depth layer, a morphological coding of jack mackerel echo traces was undertaken visually using the method proposed by Petitgas \& Levenez (1996). Four echo types similar to those described by Reid (2000) were defined (Bertrand et al. 2004a): (1) scattered fish, (2) school, (3) mixed structure, i.e. the discontinuous layer and (4) layer (Fig. 2d). The vertical and horizontal positions of each echo trace were measured, as well as their maximal length and height when possible. The $s_{\mathrm{A}}$ was measured for each echo trace; this parameter is an indicator of the echo trace biomass. Additionally, an approximation for the volume backscattering strength $\left(S_{\mathrm{v}}\right)$ was calculated for all echo traces with length and height data available using the following equation:

$$
S_{V}=10 \log _{10}\left(\frac{s_{A} D E}{\pi^{2} 1852 \mathrm{ab}}\right), \text { in dB re } 1 \mathrm{~m}^{-1}
$$

with $D E$ the length of the ESDU in nautical miles, and $a$ and $b$ the length and the height of the echo trace in metres, respectively. The $S_{\mathrm{v}}$ is an indicator of the fish density inside each collective structure (echo trace).

Oceanographic data. The oceanographic information was collected at discrete stations over the acoustic transects at $10,25,50,75,100,130,160$ and 200 nautical miles off the coast. Temperature, salinity and DO between the surface and $600 \mathrm{~m}$ were registered by a Seabird CTD. Water samplings from Niskin bottles were performed to calibrate a DO sensor. In 1999, a DO sensor was not available. In order to extract oceanographic conditions for each jack mackerel echo trace position (in the horizontal and vertical planes), oceanographic data were interpolated by transect in the vertical plane using the natural neighbour method.

Multiple ANOVAs (analysis of variance) were used to check whether depth, temperature, DO and prey abundance at locations where fish echo traces were distributed varied according to year and to echo type. It should be noted that other parameters (e.g. salinity, water density, chlorophyll concentration and moon phase) were considered in preliminary analyses, but the results are not presented here because they did not add vital information in the context of this study. Calculations were performed for day and night periods. To check for differences between each group, we used Newman-Keuls post hoc comparison tests, which 
limits potential biases in multiple testing, see Appendix 1 for detailed results of these tests.

In the case of jack mackerel, as for other oceanic pelagic fish such as tuna (Hanamoto 1987, Brill 1994, Bertrand et al. 2002b), temperature and DO can be considered the main abiotic parameters limiting the range of horizontal and vertical distribution. Therefore, we calculated vertical habitat limits for jack mackerel using a method similar to the one described by Bertrand et al. (2002b) for tropical tunas. For each parameter, we measured a threshold value below which $<2.5 \%$ of jack mackerel echoes were observed. We calculated these thresholds as well as the absolute limits (minimum) for all echo types and by echo type. Calculations were only performed during the day, when fish distribution was deeper.

\section{RESULTS}

\section{Echo type biomass and density according to diel periods}

Echo trace biomass $\left(s_{\mathrm{A}}\right)$ and density $\left(S_{\mathrm{v}}\right)$ of Trachurus murphyi varied significantly according to the diel cycle (ANOVA: $F_{[3,8281]}=308.1, p=0.0000$ for $s_{\mathrm{A}}$ and $F_{[3,2220]}=65.5, \mathrm{p}=0.0000$ for $\left.S_{\mathrm{v}}\right)$, having lower biomass and being less dense during the day than during the night (Fig. 3). When the echo type was taken into account, this trend was confirmed for the more frequent occurrences, i.e. scattered fish and schools, but results were not significant for mixed structures and layers (Fig. 4). Whatever the period, the biomass was significantly different between echo types, with a clearly increasing trend: scattered biomass $<$ school biomass < mixed structure biomass < layer biomass (Fig. 4). Finally, the echo trace frequency also varied according to the diel cycle (Fig. 2), with scattered fish more abundant during the day and schools more abundant during the night. The percentage of mixed structures and layers was also higher at night, except in 1998.

\section{Fish echo types versus abiotic and biotic factors}

\section{Depth}

Strong diel vertical migration was observed during the study period. Jack mackerel mean depth was about $100 \mathrm{~m}$ during the day and $20 \mathrm{~m}$ during the night (Bertrand et al. 2004a) (Fig. 5a,b). During the day (Fig. 5a), the mean depth of echo traces varied significantly according to the year (ANOVA: $F_{[2,4694]}=56.4$, $\mathrm{p}=0.0000$ ) and the echo type (ANOVA: $F_{[3,4694]}=$

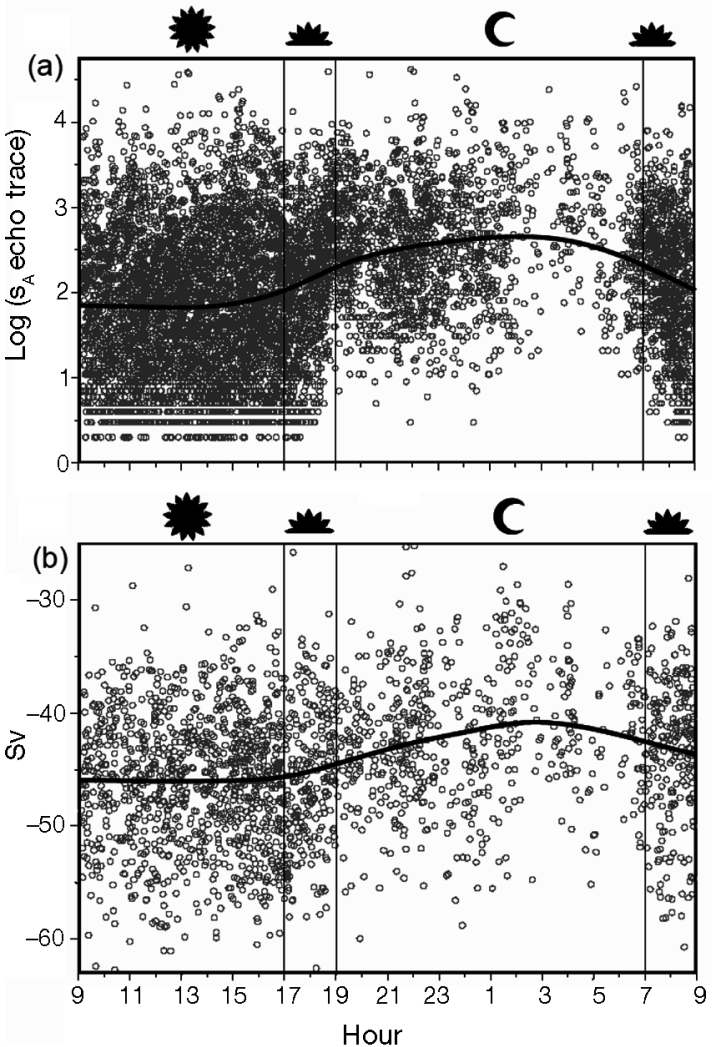

Fig. 3. Trachurus murphyi. Diel pattern (a) of the log-transformed acoustic nautical area scattering coefficient $\left(s_{\mathrm{A}}\right.$, in $\mathrm{m}^{2}$ nautical mile ${ }^{-2}$ ) and (b) of the volume backscattering strength $\left(S_{\mathrm{V}}\right.$, in $\mathrm{dB}$ re $\left.1 \mathrm{~m}^{-1}\right)$ of echo traces (circles: raw data; solid line:

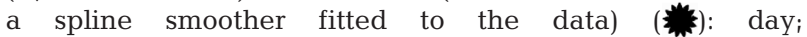
(․․․): dusk and dawn; (C): night. Note: the reduced amount of data at night is due to the lower number of samples during this period and not to a reduced ability to detect fish

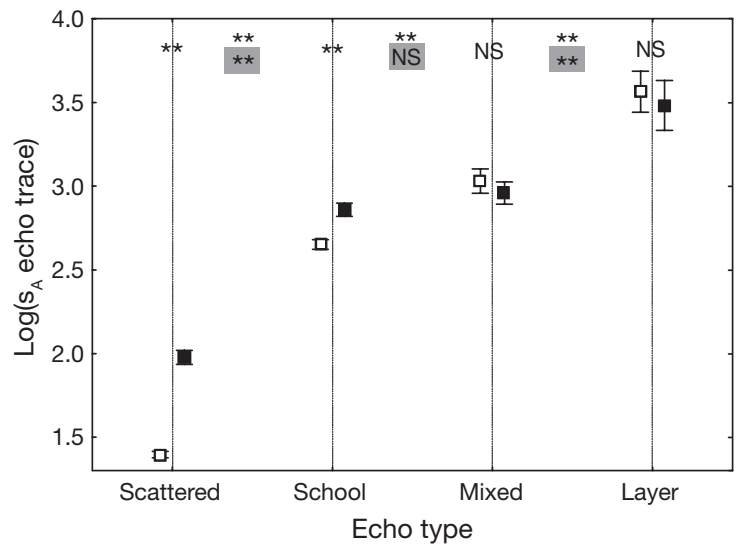

Fig. 4. Trachurus murphyi. Log-transformed acoustic nautical area scattering coefficient $\left(s_{\mathrm{A}}\right.$, in $\mathrm{m}^{2}$ nautical mile $\left.{ }^{-2}\right)$ of jack mackerel according to fish echo type, during the day ( $\square$ ) and the night (ם). Results of the ANOVA are also indicated $\left({ }^{* *}\right.$ : highly significant differences $[p<0.01]$; NS: no significant difference $[p>0.05])$. ANOVA results positioned on the inner gridlines correspond to day/night tests for the same echo type; test results between gridlines show differences between echo types, during the day (upper row of results) and during the night (grey square, lower row of results) 

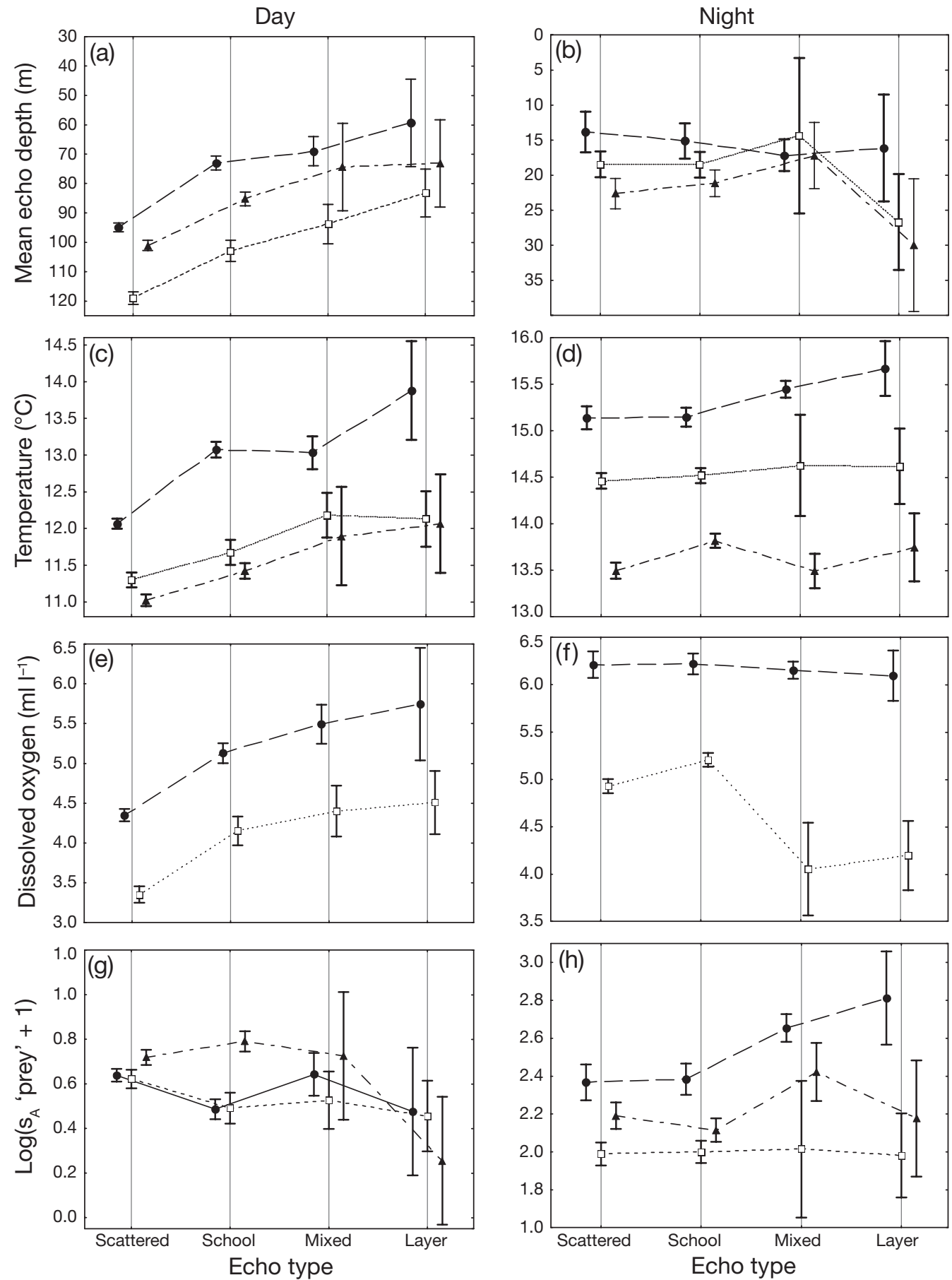

Fig. 5. Trachurus murphyi. For each echo type, depth of jack mackerel (in m) during (a) the day and (b) the night; temperature (in ${ }^{\circ} \mathrm{C}$ ) where fish echo traces were distributed during (c) the day and (d) the night; dissolved oxygen (in ml $\mathrm{l}^{-1}$ ) where fish echo traces were distributed during (e) the day and (f) the night; and log-transformed index of prey biomass during the day (g) and the night (h), where echo traces were distributed for $1997(\boldsymbol{\bullet}) 1998(\square)$ and $1999(\boldsymbol{\Delta})$. The vertical whiskers indicate the $95 \%$ confidence intervals centred on the mean

143.4, $\mathrm{p}=0.0000)$. When considering the results survey by survey, the difference between echo trace depths for each echo type was also always significant (Newman-Keuls tests). The same trend was observed each year: layer depth < mixed structure depth < school depth $<$ scattered fish depth.

During the night, the mean depth of echo traces (Fig. 5b) varied significantly according to the year 
(ANOVA: $F_{[2,1629]}=17.3, \mathrm{p}=0.0000$ ), but not according to the echo type (ANOVA: $F_{[3,1614]}=2.4, \mathrm{p}=0.0652$ ). No significant differences in echo type depth were observed (Newman-Keuls tests) when each survey/ year was considered independently.

\section{Temperature}

During the day, temperature at locations where echo traces were distributed (Fig. 5c) varied significantly according to year (ANOVA: $F_{[24544]}=66.4, \mathrm{p}=0.0000$ ) and to echo type $\left(F_{[3,4544]}=77.9, \mathrm{p}=0.0000\right)$. The temperatures at which echo traces were distributed also varied significantly according to the echo type (Newman-Keuls tests) when results were analysed survey by survey. The same trend was observed each year on daytime temperature, i.e. scattered $<$ school $<$ mixed structure < layer.

During the night, highly significant differences in temperature were observed between years where fish echo traces were distributed $\left(F_{[2,1391]}=299.7, \mathrm{p}=\right.$ $0.0000)$, with temperature decreasing from 1997 to 1999 (Fig. 5d). No significant differences were observed between echo types in 1998 (Newman-Keuls tests) and no clear trends were observed in other years in the survey by survey analysis of data.

\section{Dissolved oxygen}

Where fish echo traces were distributed (Fig. 5e) daytime DO varied significantly according to year $\left(F_{[1,2649]}=80.4\right.$, $\mathrm{p}=0.0000)$ and to echo type $\left(F_{[3,2649]}=\right.$ $79.5, p=0.0000$ ). In the survey by survey analysis, the DO difference for echo type was always significant (Newman-Keuls tests). The same trend was observed for each survey of daytime DO where echo traces were distributed, i.e. scattered $<$ school $<$ mixed structure $<$ layer.

Where echo traces were distributed (Fig. 5f) night time DO varied significantly according to year $\left(F_{[1,771]}=308.8\right.$, $\mathrm{p}=0.0000)$ and to echo type $\left(F_{[3,771]}=\right.$ $14.2, \mathrm{p}=0.0000$ ). For the same year, no significant differences were observed for echo type in 1997, and slight differences were observed for 1998 (echo types 'school' vs. 'scattered' and 'mixed' vs. 'layer' were not significantly different, Newman-Keuls tests). In contrast to results for the daytime, no clear intraannual trend appeared.
Index of prey biomass

During the day, the index of prey biomass where fish echo traces were distributed was very low (Fig. $5 \mathrm{~g}$ ). It did not vary significantly according to year $\left(F_{[2,4694]}=\right.$ $1.4, \mathrm{p}=0.2352)$, but it did vary according to echo type $\left(F_{[3,4694]}=8.1, p=0.0000\right)$ and when years were considered independently, the index was not significantly different between the echo types (Newman-Keuls tests), with the exception of the echo type 'layer' in 1999.

During the night, the index of prey biomass where fish echo traces were distributed (Fig. 5h) varied significantly according to year $\left(F_{[2,1614]}=40.0, \mathrm{p}=0.0000\right)$ and to echo type $\left(F_{[3,1614]}=3.7, \mathrm{p}=0.0119\right)$. Newman-Keuls tests showed that for the same year, no significant differences in the index of prey biomass were observed between echo types in 1998. For other years, the only echo types with a significantly higher index of prey biomass were 'layer' in 1997 and 'mixed' in 1999.

Vertical profiles of jack mackerel versus prey abundance estimates $\left(s_{\mathrm{A}}\right)$ displayed the same pattern each year (Fig. 6). During the day, jack mackerel were distributed at a depth where no or very few prey were present. In contrast, during the night, jack mackerel were distributed at the same depth as their prey. This pattern is also illustrated by the correlation between
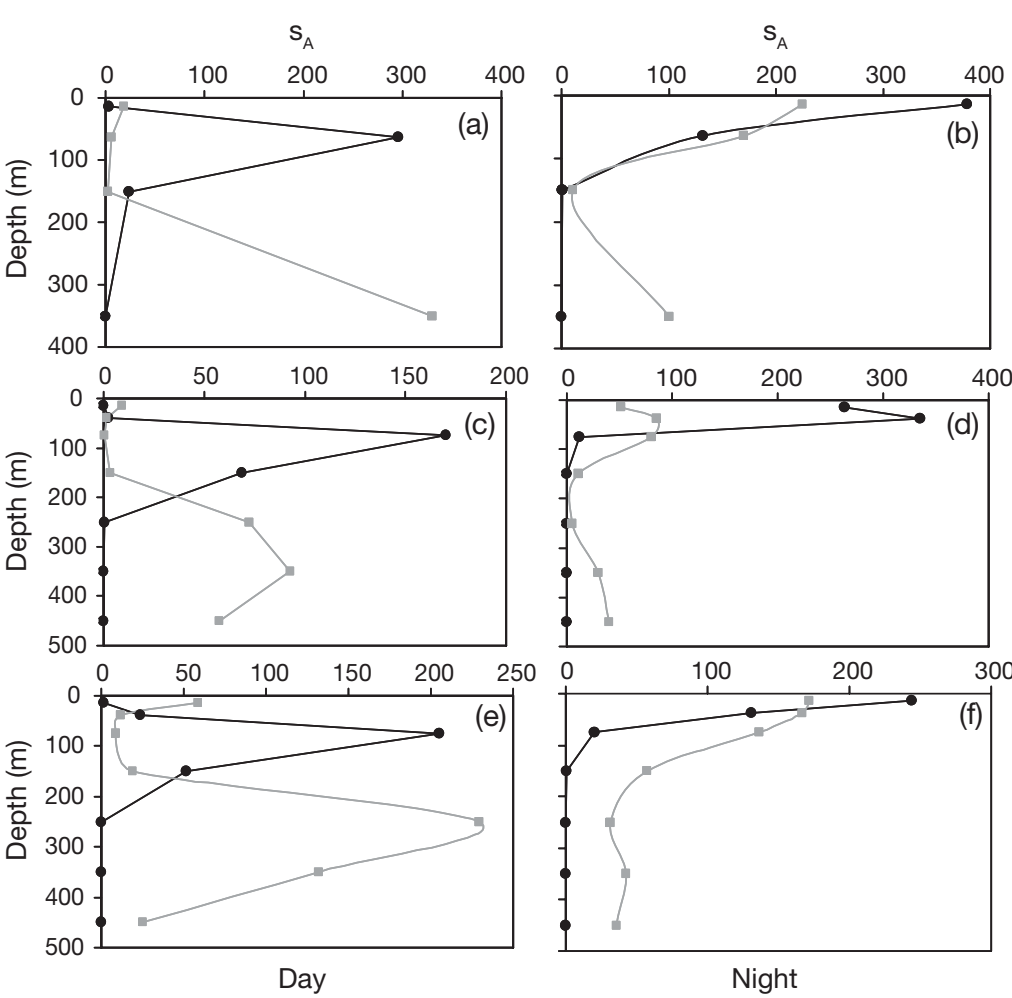

Fig. 6. Trachurus murphyi. Vertical profiles of jack mackerel (black line) and prey (grey line) acoustic nautical area scattering coefficient $\left(s_{\mathrm{A}}\right.$, in $\mathrm{m}^{2}$ nautical mile $^{-2}$ ) in 1997 during the day (a) and the night (b), in 1998 during the day (c) and the night (d) and 1999 during the day (e) and the night (f) 

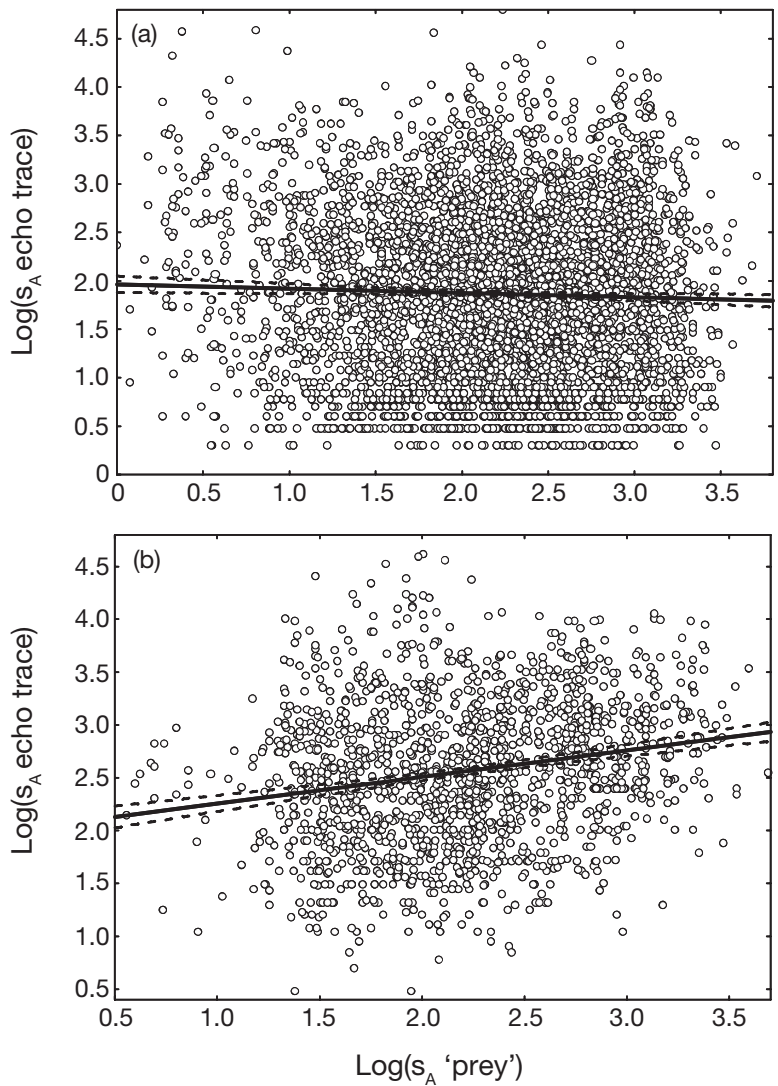

Fig. 7. Trachurus murphyi. Relation between the log-transformed acoustic nautical area scattering coefficients $\left(s_{\mathrm{A}}\right.$, in $\mathrm{m}^{2}$ nautical mile ${ }^{-2}$ ) for jack mackerel echo traces and the index of prey abundance in the water column (for details of depths, see text), during the day (a) and the night (b). The linear regression (solid black line) and 95\% confidence band (dotted black lines) are fitted on each plot

jack mackerel echo traces and prey indexes of abundance (Fig. 7) in the water column (from the surface to $500 \mathrm{~m}$ during the day and to $200 \mathrm{~m}$ during the night, see Bertrand et al. 2004a). Results showed that the correlation was slightly negative during the day $\left(F_{[1,4704]}=\right.$ $5.3, \mathrm{p}=0.0209$ ) and highly significantly positive during the night $\left(F_{[1,1630]}=73.3, \mathrm{p}=0.0000\right)$.

\section{Temperature and DO thresholds}

Thresholds calculated from all daytime data were close to $10^{\circ} \mathrm{C}$ for temperature and $1 \mathrm{ml} \mathrm{l}^{-1}$ for DO (Table 1). When the thresholds were calculated by echo type, marked differences appeared (Table 1). These differences were higher for DO than for temperature. For both parameters, differences in thresholds had the following trend: scattered $<$ school $<$ mixed structure < layer, i.e. the same trend as that observed for echo type biomass $\left(s_{\mathrm{A}}\right)$ (Fig. 4). The correlation between echo type $s_{\mathrm{A}}$ and DO thresholds is significantly positive $\left(\mathrm{R}^{2}=0.9979, \mathrm{p}<0.01\right)$, whereas it is not significant between $s_{\mathrm{A}}$ and temperature threshold $\left(\mathrm{R}^{2}=\right.$ 0.7889, p > 0.05) (Table 1).

\section{DISCUSSION}

\section{Nocturnal schooling behaviour}

The apparently 'atypical' schooling behaviour of the jack mackerel Trachurus murphyi (Bertrand et al. 2004a) was confirmed by the present study. Diel schooling behaviour was the inverse of that usually observed (Azzali et al. 1985, Fréon et al. 1996, Cardinale et al. 2003), as fish dispersed by day and aggregated in dense collective structures at night (Figs. 2 \& 3). If fish are able to school at any time of the day, light thresholds are not necessarily key parameters for schooling behaviour dynamics. A major difference between T. murphyi and other obligatory schooling fish species is its habitat since the former is mostly found in oceanic waters, i.e. not on the shelf or shelfbreak. This difference has major consequences in terms of prey accessibility since the offshore habitat is not vertically limited by geographic structures and most pelagic organisms, such as jack mackerel and their prey (mainly euphausiids and mesopalegic fish), perform vertical migration. During the day, prey are generally distributed between 250 and $400 \mathrm{~m}$, out of reach of jack mackerel. Prey become available at dusk, when they migrate toward the surface. At this point,

Table 1. Trachurus murphyi. Mean $s_{\mathrm{A}}$ of jack mackerel echo traces, temperature and dissolved oxygen (DO) concentrations below which $<2.5 \%$ of the fish were observed and their absolute lower limit, for all daytime data and by echo type (n: numbers of samples; $\mathrm{n}$ miles: nautical miles)

\begin{tabular}{|c|c|c|c|c|c|c|c|}
\hline \multirow[t]{2}{*}{ Echo } & \multirow{2}{*}{$\underset{\left(\mathrm{m}^{2} \mathrm{n} \text { mile }^{-2}\right)}{\text { Mean } S_{\mathrm{A}}}$} & \multicolumn{3}{|c|}{ Temperature $\left({ }^{\circ} \mathrm{C}\right)$} & \multicolumn{3}{|c|}{$\mathrm{DO}\left(\mathrm{ml} \mathrm{l}^{-1}\right)$} \\
\hline & & $2.5 \%$ limit & $\mathrm{n}$ & Lower limit & $2.5 \%$ limit & $\mathrm{n}$ & Lower limit \\
\hline All daytime data & 511 & 10.03 & 4556 & 8.95 & 1.08 & 2029 & 0.59 \\
\hline Scattered & 56 & 9.91 & 2959 & 8.95 & 0.98 & 962 & 0.59 \\
\hline School & 1001 & 10.19 & 1318 & 9.58 & 1.46 & 659 & 0.98 \\
\hline Mixed structure & 2067 & 10.71 & 207 & 10.57 & 1.88 & 183 & 1.16 \\
\hline Layer & 5921 & 10.92 & 72 & 10.85 & 3.96 & 58 & 3.30 \\
\hline
\end{tabular}


jack mackerel aggregate in dense schools. Thus, we may now form the following hypothesis: jack mackerel schooling behaviour depends primarily on prey availability through the diel cycle. During their feeding migration along the Chilean coast in austral winter, foraging is the first priority. When no prey are available, the fish then shift into a second behavioural pattern, i.e. resting (thus reducing their energetic consumption) in the appropriate hydrological conditions. Are our results compatible with such a hypothesis?

\section{Fish echo types versus abiotic and biotic factors}

Whatever the year and diel period, echo trace biomass $\left(s_{\mathrm{A}}\right)$ varied in a similar manner with the echo types: scattered < school < mixed structure < layer. Regarding the oceanographic conditions in which echo traces of different echo types were present, the trends were very different depending on the diel period. Fish were present in deep strata during the day, and their distribution appeared to be related to seawater characteristics (Fig. 5). Echo trace depth was inversely related to echo type mean biomass (i.e. denser and populated echo traces were distributed at lower depths). The relation was positive between echo trace biomass and temperature and DO (i.e. dense and populated denser echo traces were distributed at higher temperatures and DO).

During the night, when fish were distributed close to the surface, the picture was completely different. No trends were observed between echo types and abiotic parameters; moreover, inter-annual differences were high, reflecting the variation in oceanographic characteristics related to the beginning of the El Niño event in 1997, its end in 1998 and a La Niña event in 1999 (see Escribano et al. 2004 for a synopsis of the consequences of the 1997/1998 El Niño in Chilean waters). So, during the night, when prey were available, fish distribution was not related to the abiotic conditions. Rather, it depended on prey distribution, as illustrated by the positive correlation between fish and prey abundances (Fig. 7b) and the vertical profiles of abundance (Fig. 6). However, when taking into account the echo type in the relation between fish and prey, no trend was seen (Fig. 5h). We can interpret this result in terms of school dynamics. Dynamic fish structures are in a perpetual state of construction and collapse (Gerlotto \& Paramo 2003), leading to the presence of several types of structures in the same area. The echo types present in areas richer in prey were the most dense and most populated, i.e. 'mixed' and 'layer' (Fig. 5h). In contrast, during the day, when prey were out of reach, fish distribution appeared to be driven more by the vertical hydrological conditions.

\section{Prey out of reach: resting time}

During the day most of the prey were distributed between 200 and $300 \mathrm{~m}$ in the OMZ (mid-depth of minimum DO: about $250 \mathrm{~m}$ ). Prey were thus in a refuge zone, out of reach of jack mackerel, the vertical distribution of which was limited by the oxycline. The hypothesis that jack mackerel could also descend to a specific depth as a refuge against predation is unlikely, as their own predators (mainly swordfish, tunas and marine mammals) have a greater vertical range of distribution than the jack mackerel themselves. Actually, Trachurus murphyi probably saves energy during the day compared to during the night by resting in a water mass with lower temperatures and DO (see Alexander 1972 for energetic considerations). Indeed, as long as food is not present, the voluntary swimming speed and respiratory rate of fish are low (Durbin et al. 1981, Thetmeyer 1997). When all echo traces were considered, the relationships between the biomass of fish echo traces and DO (Fig. 8b) revealed the presence of an 'exclusion zone': echo traces with high biomass
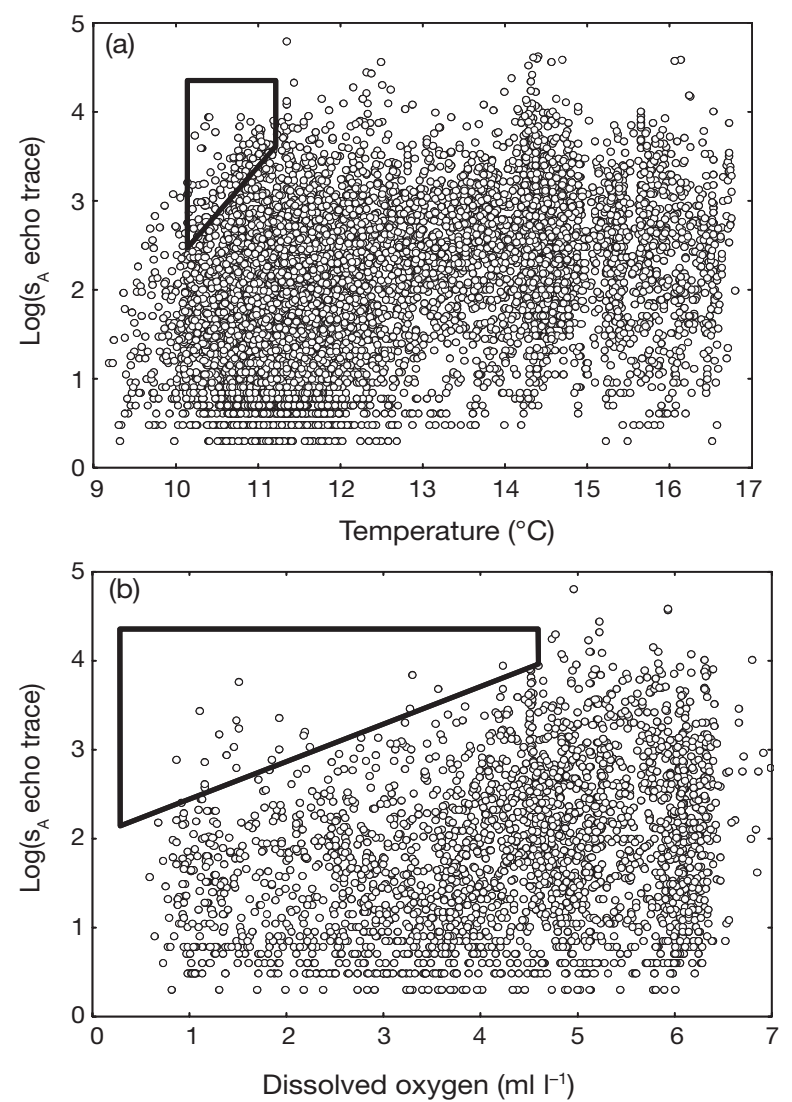

Fig. 8. Trachurus murphyi. Log-transformed acoustic nautical area scattering coefficient $\left(s_{\mathrm{A}}\right.$, in $\mathrm{m}^{2}$ nautical mile $\left.{ }^{-2}\right)$ of jack mackerel echo traces relative to (a) temperature (in ${ }^{\circ} \mathrm{C}$ ) and (b) dissolved oxygen (in $\mathrm{ml} \mathrm{l}^{-1}$ ), where distributed during the day. Polygons illustrate the 'exclusion zones' where almost no fish were observed 
were not observed in low DO concentrations. Such an 'exclusion zone' does not appear as clearly in the case of temperature (Fig. 8a). Thus, DO is likely to be a key abiotic parameter in fish vertical distribution and spatial organisation. This assumption was confirmed by threshold calculations showing clear differences according to echo type for DO and no such differences for temperature (Table 1). In fact, the DO threshold increased according to the same trend as biomass: scattered $<$ school $<$ mixed structure $<$ layer.

Studies on the impact of DO on fish schooling behaviour are scarce. However, we propose an interpretation following a 2-stage mechanism to explain why the schooling behaviour changed according to DO. First, inside a densely populated aggregation, fish respiration can lead to local DO depletion (McFarland \& Moss 1967). So, when fish are more numerous, collective oxygen consumption requires higher initial DO conditions (McFarland \& Moss 1967, Dommasnes et al. 1994, McFarland \& Okubo 1997). Second, low water temperature and DO reduce fish metabolism (Jones 1971, Kramer 1987). Lethargic fish reduce their activity (Alexander 1972, Kramer 1987, Kinzer et al. 1993, Israeli \& Kimmel 1996), which limits their schooling capability. As observed in the current study, they tend to disperse either into loose schools or to scatter individually. Such behaviour has been noted in myctophids, which reduce activity during the day when they are distributed in deep, cold waters (with no prey available) (Barham 1970). McFarland \& Moss (1967) observed that 'field data provide positive correlation between oxygen gradients within schools and drastic modification in school structure'. In the same sense, we could illustrate a correlation between habitat oxygen gradients and fish spatial organisation.

\section{Prey accessibility 'rings the bell' for foraging time}

When migrating toward the surface at dusk, prey become available to jack mackerel. 'Foraging for patchy food in a social group has immense benefits' (Pitcher \& Parrish 1993), and predators in schools are more successful at foraging on prey in schools (Major 1978, Schmitt \& Strand 1982). Jack mackerel use this strategy as they aggregate in densely populated schools to forage on mobile micronekton (e.g. Fig. 8a); the pattern would have been different for fish foraging on plankton (e.g. Mackinson et al. 1999). In the case of Trachurus murphyi, active schooling is fairly independent of abiotic condition (light intensity included). Such behaviour reveals the jack mackerel paradox: this fish has to reach its highest level of school organisation under the lowest light intensity level. However, (1) jack mackerel have high low-light vision capabilities (Hunter 1968), and (2) we still have much to learn about the non-visual stimuli that drive schooling behaviour.

\section{CONCLUSIONS}

We propose a schematic model for jack mackerel behaviour in relation to their biotic and abiotic environment, whereby prey are available only at night (Fig. 9b).
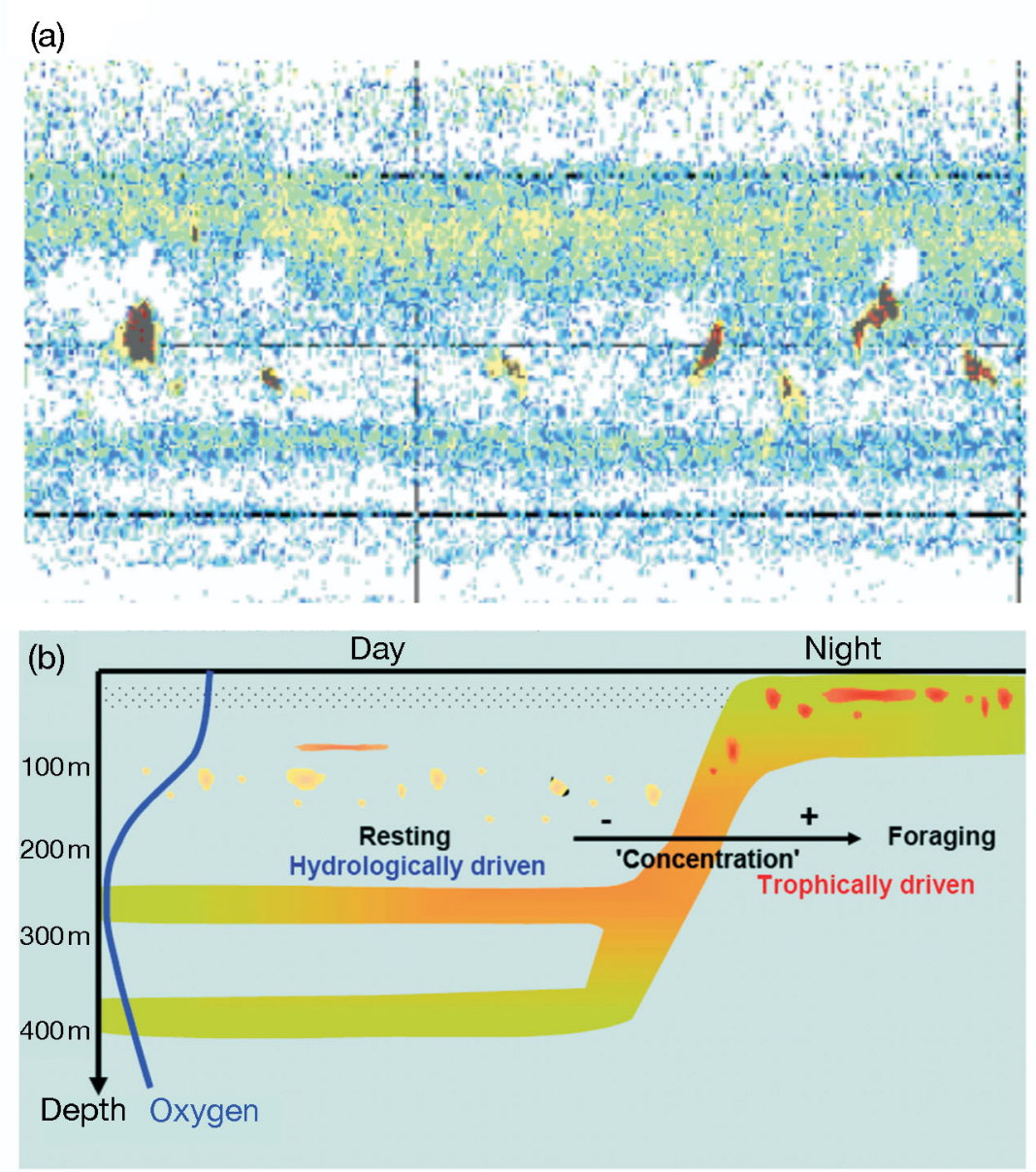

Fig. 9. Trachurus murphyi. (a) Example of jack mackerel (dark red, dense echo traces) foraging on mesopelagic communities (other echo traces) at night. (b) Schematic model of jack mackerel distribution and schooling behaviour as influenced by biotic and abiotic conditions across the diel cycle. Jack mackerel are represented by yellow to red small structures (fish abundance and density increasing from yellow to red). Prey are represented by continuous layers (green to orange) 
At dawn, the mesopelagic communities constituting jack mackerel prey migrate into, or below, the OMZ (some of the mesopelagic communities migrate to about 400 to $500 \mathrm{~m}$ below the OMZ). During the day, prey are in a refuge zone. Jack mackerel reduce their activity and rest in cold waters $\left(10^{\circ} \mathrm{C}\right)$ in the upper part of the oxycline (DO $1 \mathrm{ml} \mathrm{l}^{-1}$ ). Their schooling behaviour is weakened, and fish are mainly distributed in loose schools or as scattered individuals. At dusk, the landscape changes quickly with the vertical ascent of the mesopelagic communities that become available to jack mackerel. Fish adapt their schooling behaviour and concentrate to forage in dense schools. Fish distribution is no longer related to hydrological conditions, but reflects the prey distribution across scales (Bertrand et al. 2004a); this behaviour is observed throughout the night.

In winter, fishers target these dense, nocturnal structures (Hancock et al. 1995). Since prey accessibility is a key factor in jack mackerel schooling behaviour, this also strongly affects their vulnerability to the purseseine fishery (Bertrand et al. 2004a). A very interesting point is that, during recent winter surveys (post-2002), areas in which prey was available during the day were observed (Instituto de Fomento Pesquero unpubl. data). It has been observed elsewhere that mesopelagic fish can form diurnal surface aggregations under specific oceanographic conditions (Marchal \& Lebourges 1996, Bertrand et al. 2002a). Where prey were available, jack mackerel aggregated and foraged during the daytime. When such a phenomenon occurs, local fishers say that fish are 'working by day'.

The 'atypical' behaviour we observed can be considered a typical adaptation of obligatory gregarious pelagic fish to an oceanic ecosystem. When necessary, fish can adapt their schooling behaviour to make it compatible to their needs regarding the hydrological and trophic constraints of the ecosystem. Fish schooling behaviour is not necessarily driven by the diel cycle. The determinism can be functional and depend, for example, on prey availability or on physiological and behavioural priorities. One initial operational consequence is that echo types can be considered good indicators of the way fish function in relation to their environment.

Acknowledgements. The authors thank the council of the 'Fondo de Investigación Pesquera', Chile, which authorised the use of data for this work. We are also grateful to E. Poulain and S. Bertrand for very useful discussions. Special thanks are due to G. Swartzman for improving the contents and the English. The comments of 3 anonymous reviewers helped to improve the paper. This work is a contribution of the Research Units 'Active' URO61 and 'Upwelling Ecosystems' UR097 and of the Interdepartmental Thematic Action 'Humboldt Current System' of the Institut de Recherche pour le Développement.

\section{LITERATURE CITED}

Alexander RM (1972) The energetics of vertical migration by fishes. Symp Soc Exp Biol 26:273-294

Arntz WE, Fahrbach E (1996) El Niño: experimento climático de la naturaleza. Fondo de cultura económica, Mexico City

Azzali M, Buracchi G, Conti S, Gambetti S, Luna M (1985) Relationship between the forms of pelagic fish distribution and nictemeral periods. A tentative model of behaviour. Oebalia 11:471-488

Barbieri MA, Córdova J, Lillo S (1998) Evaluación hidroacústica del recurso jurel en la zona centro-sur (fase crucero metodológico). Informe final Fondo de Investigación Pesquera no. 95-07, Instituto de Fomento Pesquero, Santiago

Barham EG (1970) Deep sea fishes: lethargy and vertical orientation. In: Farquahar GB (ed) Biological sound scattering in the ocean, Report 005, US Government Printing Office. Maury Center for Ocean Science, Washington, DC, p 100-118

Bertrand A, Le Borgne R, Josse E (1999) Acoustic characterisation of micronekton distribution in French Polynesia. Mar Ecol Prog Ser 191:127-140

Bertrand A, Bard F-X, Josse E (2002a) Tuna food habits related to the micronekton distribution in French Polynesia. Mar Biol 140:1023-1037

Bertrand A, Josse E, Bach P, Gros P, Dagorn L (2002b) Hydrological and trophic characteristics of tuna habitat: consequences on tuna distribution and longline catchability. Can J Fish Aquat Sci 59:1002-1013

Bertrand A, Barbieri MA, Córdova J, Hernández C, Gómez F, Leiva F (2004a) Diel vertical behaviour, predator-prey relationships, and occupation of space by jack mackerel (Trachurus murphyi) off Chile. ICES J Mar Sci 61: 1105-1112

Bertrand A, Segura M, Gutiérrez M, Vasquez L (2004b) From small-scale habitat loopholes to decadal cycles: a habitatbased hypothesis explaining fluctuation in pelagic fish populations off Peru. Fish Fish 5:296-316

Brill RW, Dewar H, Graham JB (1994) Basic concepts relevant to heat transfer in fishes, and their use in measuring the physiological thermoregulatory abilities of tunas. Environ Biol Fishes 40:109-124

Cardinale M, Casini M, Arrhenius F, Håkansson N (2003) Diel spatial distribution and feeding activity of herring (Clupea harengus) and sprat (Sprattus sprattus) in the Baltic Sea. Aquat Living Resour 16:283-292

Córdova J, Barbieri MA, Lillo S (1998) Evaluación hidroacústica de jurel en la ZEE de Chile. Instituto de Fomento Pesquero, Santiago

Córdova J, Barbieri MA, Lillo S (1999) Evaluación hidroacústica de jurel en la ZEE de Chile. Instituto de Fomento Pesquero, Santiago

Córdova J, Barbieri MA, Lillo S (2000) Evaluación hidroacústica de jurel en la ZEE de Chile. Instituto de Fomento Pesquero, Santiago

Dommasnes A, Rey F, Røttingen I (1994) Reduced oxygen concentration in herring wintering areas. ICES J Mar Sci 51:63-69

Durbin AG, Durbin EG, Verity PG, Smayda TJ (1981) Voluntary swimming speeds and respiration rates of a filterfeeding planktivore, the Atlantic menhaden, Brevoortia tyrannus (Pices: Clupidae). Fish Bull 78:877-886

Escribano R, Daneri G, Farías L, Gallardo VA and 7 others (2004) Biological and chemical consequences of the 1997-1998 El Niño in the Chilean coastal upwelling system: a synthesis. Deep-Sea Res II 51:2389-2411 
Fréon P, Misund OA (1999) Dynamics of pelagic fish distribution and behaviour: effects on fisheries and stock assessment. Blackwell Science, Oxford

Fréon P, Gerlotto F, Soria M (1996) Diel variability of school structure with special reference to transition periods. ICES J Mar Sci 53:459-464

Gerlotto F, Paramo J (2003) The three-dimensional morphology and internal structure of clupeid schools as observed using vertical scanning multibeam sonar. Aquat Living Resour 16:113-122

Grechina A (1998) Historia de investigaciones y aspectos básicos de la ecología del jurel Trachurus symmetricus murphyi (Nichols) en alta mar del Pacífico Sur. In: Arcos D (ed) Biología y ecología del jurel en aguas Chilenas. Instituto de Investigación Pesquera, Concepción, Chile, p 11-34

Hanamoto E (1987) Effect of oceanographic environment on bigeye tuna distribution. Bull Jpn Soc Fish Oceanogr 51: 203-216

Hancock J, Hart JB, Antezana T (1995) Searching behaviour and catch of horse mackerel (Trachurus murphyi) by industrial purse-seiners off south-central Chile. ICES J Mar Sci 52:991-1004

Hunter JR (1968) Effects of light on schooling and feeding of jack mackerel, Trachurus symmetricus. J Fish Res Board Can 25:393-407

Israeli D, Kimmel E (1996) Monitoring the behavior of hypoxia-stressed Carassius auratus using computer vision. Aquacult Eng 15:423-440

Jones DR (1971) The effect of hypoxia and anaemia on the swimming performance of rainbow trout (Salmo gairdneri). J Exp Biol 55:541-551

Kinzer J, Böttger-Schnack R, Schulz K (1993) Aspects of horizontal distribution and diet of myctophid fish in the Arabian Sea with reference to the deep water oxygen deficiency. Deep-Sea Res II 40:783-800

Konchina YV (1981) The Peruvian jack mackerel, Trachurus symmetricus murphyi, a facultative predator in the coastal upwelling ecosystem. J Ichthyol 21:46-59

Kramer DL (1987) Dissolved oxygen and fish behavior. Environ Biol Fishes 18:81-92

Mackinson S, Nøttestad L, Guénette S, Pitcher T, Misund OA, Ferno A (1999) Cross-scale observations on distribution and behavioural dynamics of ocean feeding Norwegian spring-spawning herring (Clupea harengus L.). ICES J Mar Sci 56:613-626

MacLennan DN, Fernandes PG, Dalen J (2002) A consistent approach to definitions and symbols in fisheries acoustics. ICES J Mar Sci 59:365-369

Major PF (1978) Predator-prey interactions in two schooling fishes, Caranx ignobilis and Stolephorus purpureus. Anim Behav 26:760-777

Marchal E, Lebourges A (1996) Acoustic evidence for unusual diel behaviour of a mesopelagic fish (Vincinguerria nimbaria) exploited by tuna. ICES J Mar Sci 53:443-447

McFarland WN, Moss SA (1967) Internal behavior in fish schools. Science 156:260-262

McFarland W, Okubo A (1997) Metabolic models of fish school behavior - the need for quantitative observations. In: Parrish JK, Hammer WM (eds) Animal groups in three dimensions. Cambridge University Press, Cambridge, p 301-312

Petitgas P, Levenez JJ (1996) Spatial organisation of pelagic fish: echogram structure, spatio-temporal condition, and biomass in Senegalese waters. ICES J Mar Sci 53:147-153

Pitcher TJ, Parrish JK (1993) Function of shoaling behaviour in teleost. In: Pitcher TJ (ed) Behaviour of teleost fishes, 2nd edn. Chapman \& Hall, London, p 363-439

Reid D (2000) Report on echo trace classification. ICES Coop Res Rep 238

Sameoto DD (1986) Influence of the biological and physical environment on the vertical distribution of mesozooplankton and micronekton in the eastern tropical Pacific. Mar Biol 93:263-279

Schmitt RJ, Strand SW (1982) Cooperative foraging by yellowtail, Seriola lalandei (Carangidae), on two species of fish prey. Copeia 3:714-717

Serra R (1991) Important life history aspects of the Chilean jack mackerel, Trachurus symmetricus murphyi. Investing Pesq 36:67-83

Thetmeyer H (1997) Diel rhythms of swimming activity and oxygen consumption in Gobiusculus flavescens (Fabricius) and Pomatoschistus minutus (Pallas) (Teleostei: Gobiidae). J Exp Mar Biol Ecol 218:197-198

Wishner KF, Gowing MM, Gelfam C (2000) Living in suboxia: ecology of an Arabian Sea oxygen minimum zone copepod. Limnol Oceanogr 45:1576-1593 
Appendix 1. The p-values of Newman-Keuls post hoc comparison tests for (a) echo trace depth, (b) temperature, (c) oxygen and (d) prey biomass, according to year and to echo type (standard print: daytime data; bold print: nighttime data; italic print: significant differences $[\mathrm{p}<0.05])$

\begin{tabular}{|c|c|c|c|c|c|c|c|c|c|c|c|c|c|}
\hline & Echo type & $\begin{array}{c}1997 \\
\text { Scattered }\end{array}$ & $\begin{array}{c}1997 \\
\text { School }\end{array}$ & $\begin{array}{c}1997 \\
\text { Mixed }\end{array}$ & $\begin{array}{l}1997 \\
\text { Layer }\end{array}$ & $\begin{array}{c}1998 \\
\text { Scattered }\end{array}$ & $\begin{array}{c}1998 \\
\text { School }\end{array}$ & $\begin{array}{c}1998 \\
\text { Mixed }\end{array}$ & $\begin{array}{l}1998 \\
\text { Layer }\end{array}$ & $\begin{array}{c}1999 \\
\text { Scattered }\end{array}$ & $\begin{array}{c}1999 \\
\text { School }\end{array}$ & $\begin{array}{c}1999 \\
\text { Mixed }\end{array}$ & $\begin{array}{l}1999 \\
\text { Layer }\end{array}$ \\
\hline \multicolumn{14}{|c|}{ (a) Echo trace depth } \\
\hline 1997 & Scattered & & 0.0050 & 0.0004 & 0.0000 & 0.0003 & 0.3722 & 0.8533 & 0.2093 & 0.3028 & 0.2401 & 0.0059 & 0.0040 \\
\hline 1997 & School & 0.9443 & & 0.5027 & 0.0602 & 0.0000 & 0.0000 & 0.0072 & 0.3242 & 0.0001 & 0.2511 & 0.9699 & 0.9830 \\
\hline 1997 & Mixed & 0.9230 & 0.8700 & & 0.1098 & 0.0000 & 0.0000 & 0.0007 & 0.1238 & 0.0000 & 0.0750 & 0.8018 & 0.7684 \\
\hline 1997 & Layer & 0.9418 & 0.8065 & 0.7967 & & 0.0000 & 0.0000 & 0.0000 & 0.0010 & 0.0000 & 0.0004 & 0.0895 & 0.1001 \\
\hline 1998 & Scattered & 0.9137 & 0.9234 & 0.9447 & 0.9385 & & 0.0074 & 0.0003 & 0.0000 & 0.0078 & 0.0000 & 0.0000 & 0.0000 \\
\hline 1998 & School & 0.9430 & 0.9605 & 0.9871 & 0.9762 & 0.9889 & & 0.4216 & 0.0130 & 0.7560 & 0.0261 & 0.0001 & 0.0000 \\
\hline 1998 & Mixed & 0.8928 & 0.8512 & 0.9009 & 0.9020 & 0.9143 & 0.9484 & & 0.1832 & 0.4440 & 0.1533 & 0.0069 & 0.0053 \\
\hline 1998 & Layer & 0.0552 & 0.0976 & 0.2153 & 0.1490 & 0.2468 & 0.1783 & 0.0695 & & 0.0244 & 0.7399 & 0.1434 & 0.2138 \\
\hline 1999 & Scattered & 0.4693 & 0.5790 & 0.7529 & 0.6730 & 0.7285 & 0.5631 & 0.5102 & 0.3152 & & 0.0409 & 0.0001 & 0.0001 \\
\hline 1999 & School & 0.6701 & 0.7475 & 0.8586 & 0.8116 & 0.7798 & 0.5105 & 0.6982 & 0.3578 & 0.7162 & & 0.1711 & 0.1843 \\
\hline 1999 & Mixed & 0.9606 & 0.9556 & 0.9903 & 0.9607 & 0.7574 & 0.9442 & 0.9560 & 0.1747 & 0.6632 & 0.7603 & & 0.8304 \\
\hline 1999 & Layer & 0.0036 & 0.0088 & 0.0321 & 0.0172 & 0.0491 & 0.0362 & 0.0052 & 0.4144 & 0.1628 & 0.1276 & 0.0260 & \\
\hline \multicolumn{14}{|c|}{ (b) Temperature where echo traces were distributed } \\
\hline 1997 & Scattered & & 0.0029 & 0.0035 & 0.0000 & 0.0393 & 0.3239 & 0.9734 & 0.9697 & 0.0018 & 0.0850 & 0.5373 & 0.9952 \\
\hline 1997 & School & 0.9767 & & 0.8774 & 0.0031 & 0.0000 & 0.0000 & 0.0030 & 0.0029 & 0.0000 & 0.0000 & 0.0003 & 0.0020 \\
\hline 1997 & Mixed & 0.2212 & 0.1032 & & 0.0053 & 0.0000 & 0.0000 & 0.0018 & 0.0026 & 0.0000 & 0.0000 & 0.0004 & 0.0022 \\
\hline 1997 & Layer & 0.0207 & 0.0121 & 0.2221 & & 0.0000 & 0.0000 & 0.0000 & 0.0000 & 0.0000 & 0.0000 & 0.0000 & 0.0000 \\
\hline 1998 & Scattered & 0.0019 & 0.0025 & 0.0000 & 0.0000 & & 0.3507 & 0.0260 & 0.0370 & 0.3114 & 0.6495 & 0.1239 & 0.0543 \\
\hline 1998 & School & 0.0038 & 0.0055 & 0.0000 & 0.0000 & 0.7516 & & 0.4254 & 0.4532 & 0.0783 & 0.3540 & 0.4144 & 0.4749 \\
\hline 1998 & Mixed & 0.0050 & 0.0127 & 0.0001 & 0.0000 & 0.7999 & 0.8240 & & 0.8465 & 0.0007 & 0.0777 & 0.8336 & 0.9058 \\
\hline 1998 & Layer & 0.0117 & 0.0201 & 0.0001 & 0.0000 & 0.6688 & 0.5903 & 0.9566 & & 0.0013 & 0.0982 & 0.8289 & 0.8180 \\
\hline 1999 & Scattered & 0.0000 & 0.0000 & 0.0000 & 0.0000 & 0.0000 & 0.0000 & 0.0000 & 0.0000 & & 0.3070 & 0.0116 & 0.0024 \\
\hline 1999 & School & 0.0000 & 0.0000 & 0.0000 & 0.0000 & 0.0005 & 0.0004 & 0.0001 & 0.0001 & 0.1840 & & 0.1893 & 0.1248 \\
\hline 1999 & Mixed & 0.0000 & 0.0000 & 0.0000 & 0.0000 & 0.0000 & 0.0000 & 0.0000 & 0.0000 & 0.9819 & 0.2827 & & 0.8076 \\
\hline 1999 & Layer & 0.0000 & 0.0000 & 0.0000 & 0.0000 & 0.0003 & 0.0002 & 0.0000 & 0.0000 & 0.1711 & 0.6973 & 0.3454 & \\
\hline \multicolumn{14}{|c|}{ (c) Dissolved oxygen where echo traces were distributed } \\
\hline 1997 & Scattered & & 0.0065 & 0.0000 & 0.0000 & 0.0001 & 0.4057 & 0.8366 & 0.7867 & & & & \\
\hline 1997 & School & 0.9587 & & 0.1291 & 0.0277 & 0.0000 & 0.0005 & 0.0068 & 0.0099 & & & & \\
\hline 1997 & Mixed & 0.7506 & 0.9275 & & 0.2940 & 0.0000 & 0.0000 & 0.0000 & 0.0001 & & & & \\
\hline 1997 & Layer & 0.7921 & 0.8962 & 0.7394 & & 0.0000 & 0.0000 & 0.0000 & 0.0000 & & & & \\
\hline 1998 & Scattered & 0.0000 & 0.0000 & 0.0000 & 0.0000 & & 0.0009 & 0.0001 & 0.0000 & & & & \\
\hline 1998 & School & 0.0000 & 0.0000 & 0.0000 & 0.0000 & 0.1204 & & 0.5530 & 0.4426 & & & & \\
\hline 1998 & Mixed & 0.0000 & 0.0000 & 0.0000 & 0.0000 & 0.0000 & 0.0000 & & 0.6500 & & & & \\
\hline 1998 & Layer & 0.0000 & 0.0000 & 0.0000 & 0.0000 & 0.0001 & 0.0000 & 0.4251 & & & & & \\
\hline \multicolumn{14}{|c|}{ (d) Index of prey biomass where echo traces were distributed } \\
\hline & & 0.6384 & 0.4855 & 0.6423 & 0.4755 & 0.6212 & 0.4909 & 0.5263 & 0.4553 & 0.7182 & 0.7904 & 0.7256 & 0.2552 \\
\hline 1997 & Scattered & & 0.6793 & 0.9734 & 0.7235 & 0.8820 & 0.5805 & 0.5973 & 0.6953 & 0.7703 & 0.6839 & 0.8757 & 0.0212 \\
\hline 1997 & School & 0.8934 & & 0.7554 & 0.9309 & 0.6454 & 0.9628 & 0.9342 & 0.9632 & 0.4097 & 0.1737 & 0.4336 & 0.1927 \\
\hline 1997 & Mixed & 0.1240 & 0.0976 & & 0.7805 & 0.9819 & 0.6876 & 0.7488 & 0.7424 & 0.5124 & 0.5767 & 0.7523 & 0.0237 \\
\hline 1997 & Layer & 0.0060 & 0.0060 & 0.2281 & & 0.7174 & 0.9903 & 0.9719 & 0.8618 & 0.4185 & 0.1664 & 0.4335 & 0.1385 \\
\hline 1998 & Scattered & 0.0585 & 0.0506 & 0.0000 & 0.0000 & & 0.4992 & 0.4127 & 0.7078 & 0.8369 & 0.6897 & 0.8967 & 0.0266 \\
\hline 1998 & School & 0.0565 & 0.0512 & 0.0000 & 0.0000 & 0.9308 & & 0.7605 & 0.9899 & 0.3650 & 0.1615 & 0.3988 & 0.2496 \\
\hline 1998 & Mixed & 0.0539 & 0.0522 & 0.0001 & 0.0000 & 0.9797 & 0.9156 & & 0.9732 & 0.4614 & 0.2539 & 0.5184 & 0.1785 \\
\hline 1998 & Layer & 0.0627 & 0.0524 & 0.0000 & 0.0000 & 0.9527 & 0.9883 & 0.9944 & & 0.3615 & 0.1255 & 0.3678 & 0.0842 \\
\hline 1999 & Scattered & 0.1775 & 0.2994 & 0.0036 & 0.0000 & 0.6352 & 0.5901 & 0.5298 & 0.6799 & & 0.8073 & 0.9491 & 0.0026 \\
\hline 1999 & School & 0.2163 & 0.2368 & 0.0007 & 0.0000 & 0.7693 & 0.6541 & 0.4399 & 0.8442 & 0.8311 & & 0.5758 & 0.0003 \\
\hline 1999 & Mixed & 0.9084 & 0.7767 & 0.0752 & 0.0080 & 0.0261 & 0.0277 & 0.0301 & 0.0261 & 0.2898 & 0.1760 & & 0.0024 \\
\hline 1999 & Layer & 0.3103 & 0.3819 & 0.0035 & 0.0000 & 0.6063 & 0.5335 & 0.4295 & 0.6694 & 0.9110 & 0.6400 & 0.3294 & \\
\hline
\end{tabular}

Editorial responsibility: Otto Kinne (Editor-in-Chief), Oldendorf/Luhe, Germany
Submitted: April 27, 2005; Accepted: October 11, 2005

Proofs received from author(s): March 8, 2006 